\title{
The Identification and Conservation of Tunicaminyluracil-Related Biosynthetic Gene Clusters in Several Rathayibacter Species Collected From Australia, Africa, Eurasia, and North America
}

OPEN ACCESS

Edited by:

Kira Makarova

National Center for Biotechnology Information (NLM), United States

Reviewed by:

Ilya Andreevich Osterman,

Skolkovo Institute of Science

and Technology, Russia

Anastasia Nikolskaya,

National Center for Biotechnology Information (NLM), United States

*Correspondence:

Elizabeth E. Rogers elizabeth.rogers@usda.gov

Specialty section: This article was submitted to

Evolutionary and Genomic Microbiology,

a section of the journal

Frontiers in Microbiology

Received: 08 October 2019 Accepted: 03 December 2019

Published: 10 January 2020

Citation:

Tancos MA, Sechler AJ,

Davis EW II, Chang JH,

Schroeder BK, Murray TD and Rogers EE (2020) The Identification and Conservation

of Tunicaminyluracil-Related Biosynthetic Gene Clusters in Several Rathayibacter Species Collected From Australia, Africa, Eurasia, and North America.

Front. Microbiol. 10:2914. doi: 10.3389/fmicb.2019.02914
Matthew A. Tancos ${ }^{1}$, Aaron J. Sechler', Edward W. Davis II2, Jeff H. Chang'2, Brenda K. Schroeder ${ }^{3}$, Timothy D. Murray ${ }^{4}$ and Elizabeth E. Rogers ${ }^{1 *}$

${ }^{1}$ Foreign Disease-Weed Science Research Unit, United States Department of Agriculture-Agricultural Research Service, Frederick, MD, United States, ${ }^{2}$ Department of Botany and Plant Pathology, Oregon State University, Corvallis, OR, United States, ${ }^{3}$ Department of Entomology, Plant Pathology and Nematology, University of Idaho, Moscow, ID, United States, ${ }^{4}$ Department of Plant Pathology, Washington State University, Pullman, WA, United States

Tunicaminyluracil antibiotics are a novel class of toxigenic glycolipids that are synthesized by several soil-associated Actinomycetes. The acquisition of a tunicaminyluracil biosynthetic gene cluster (TGC) in Rathayibacter toxicus has led to the emergence of the only described, naturally occurring tunicaminyluracil-associated mammalian disease, annual ryegrass toxicity of livestock. Endemic to Australia, $R$. toxicus is obligately vectored by Anguinid seed gall nematodes to the developing seedheads of forage grasses, in which the bacteria synthesize tunicaminyluracils that may subsequently be consumed by livestock and result in high rates of mortality and morbidity. The potential impact of $R$. toxicus on U.S. agriculture has led the U.S. Department of Agriculture - Animal and Plant Health Inspection Service to list $R$. toxicus as a Plant Pathogen Select Agent. R. toxicus is the only characterized phytopathogenic bacterium to produce tunicaminyluracils, but numerous $R$. toxicuslike livestock poisonings outside Australia suggest additional bacterial sources of tunicaminyluracils may exist. To investigate the conservation of the TGC in $R$. toxicus and whether the TGC is present in other Rathayibacter species, we analyzed genome sequences of members of the Rathayibacter genus. Putative TGCs were identified in genome sequences of $R$. toxicus, $R$. iranicus, $R$. agropyri, and an undescribed South African Rathayibacter species. In the latter three species, the putative TGCs have homologs of tunicaminyluracil-related genes essential for toxin production, but the TGCs differ in gene number and order. The TGCs appear at least partially functional because in contrast to atoxigenic species, TGC-containing Rathayibacter species were each able to tolerate exogenous applications of tunicamycin from Streptomyces chartreusis. The North American $R$. agropyri TGC shows extensive diversity among the sequenced isolates, with presense/absense polymorphisms in multiple genes or even the whole TGC. R. agropyri TGC structure does not appear to correlate with date or location 
of isolate collection. The conservation and identification of tunicaminyluracil-related gene clusters in three additional Rathayibacter species isolated from South Africa, the Middle East, and the United States, suggests a wider global distribution of potentially neurotoxigenic plant-associated bacteria. This potential for additional endemic and exotic toxigenic Rathayibacter species could have widespread and severe implications for agriculture.

Keywords: Rathayibacter, toxicus, iranicus, agropyri, tunicaminyluracil, tunicamycin, Anguina nematode

\section{INTRODUCTION}

Rathayibacter toxicus is a nematode-transmitted Actinobacterium that is endemic to Australia and infects a variety of forage grasses through its close association with Anguinid seed gall nematodes (Price et al., 1979; Bird, 1981). Due to its ability to synthesize a neurotoxigenic tunicaminyluracil antibiotic, it was listed as a Plant Pathogen Select Agent by the U.S. Department of Agriculture - Animal and Plant Health Inspection Service in 2008 (Murray et al., 2015). Animals that consume $R$. toxicus- infected plant material develop bacterial toxicosis-related symptoms, which are referred to as "annual ryegrass toxicity" or "flood plain staggers" (McKay et al., 1993). Poisoned animals display a variety of neurological symptoms including convulsions, paralysis, excessive salivation, muscle and head tremors, abortions, and death (Bourke et al., 1992; Finnie, 2006).

Mammalian disease symptoms are mainly neurological due to the toxin inhibiting $N$-linked glycosylation, which impairs the cardiovascular system and leads to oxygen deprivation and tissue damage (Jago et al., 1983; Finnie and Jago, 1985; Bourke et al., 1992; Finnie, 2006). Bacterial toxicosis caused by R. toxicus poisoning has resulted in severe losses for the Australian livestock industry. From 1970 to 1974, 58 outbreaks were reported in Western Australia, which resulted in the loss of thousands of sheep and cattle with morbidity and mortality rates reaching 100 and 77\%, respectively (Berry and Wise, 1975). Similar devastating outbreaks reoccurred in the early 1990s in New South Wales, Australia, with the deaths of thousands of grazing livestock (Davis et al., 1995). The association of toxicosis to $R$. toxicus has only been implicated in Australia, but other undiagnosed R. toxicuslike poisoning events have been reported outside the country (Mullins, 1941; Haag, 1943; Shaw and Muth, 1949; Cunningham and Hartley, 1959; Galloway, 1961; Schneider, 1981).

In South Africa, between 1979 and 1980, R. toxicus-like poisoning symptoms were observed in sheep and cattle that were fed plant material infected with nematode and bacterial galls, from which a Rathayibacter species was isolated (Schneider, 1981). In 2009, several horses died in the same Western Cape Province of South Africa after consuming infected plant material (Grewar et al., 2009). A suspected toxigenic Rathayibacter species was isolated from dune grass (Ehrharta villosa var. villosa) leaf galls in 2003 from the same South African region and labeled as 'woodii' due to its co-isolation and association with the leaf gall nematode Anguina woodi (Riley and Swart, 2004; Riley et al., 2004; Murray et al., 2017). Additional livestock poisonings, with symptoms similar to $R$. toxicus poisoning, were documented in New Zealand and the United States during the mid-twentieth century (Mullins, 1941; Haag, 1943; Shaw and Muth, 1949; Cunningham and Hartley, 1959; Galloway, 1961). Several livestock neurological poisonings in Oregon between 1943-1961 were associated with grasses contaminated with Anguina species galls, but no toxigenic bacteria were identified or confirmed to be the causative agents in these cases (Haag, 1943; Shaw and Muth, 1949; Galloway, 1961; Jensen, 1961).

Tunicaminyluracils are a novel class of toxigenic nucleoside antibiotics that possess a unique 11-carbon tunicamine backbone, $\mathrm{N}$-acetylglucosamine, uracil, and an assortment of fatty acid chains that vary amongst members in the class (Takatsuki et al., 1971; Edgar et al., 1982; Chen et al., 2016). Tunicaminyluracil antibiotics possess broad biological activity against prokaryotes and eukaryotes and inhibit bacterial cell wall biosynthesis and protein glycosylation, respectively (Takatsuki et al., 1971; Tkacz and Lampen, 1975). The ability to synthesize these unique and toxic antibiotics appears to be limited to soilassociated Actinomycetes, notably saprophytic Streptomyces species. Recently, a putative tunicaminyluracil biosynthetic gene cluster (TGC) was identified in the genome sequences of $R$. toxicus (Sechler et al., 2017). 'Tunicamycin' refers to the specific toxin produced by Streptomyces chartreusis; therefore the terms 'tunicaminyluracil' and 'tunicaminyluracil antibiotic' are used here to describe toxins produced by Rathayibacter since their exact structure is not known.

Rathayibacter toxicus persists in both soil and plant environments, the latter of which exposes livestock to an otherwise soil-associated antibiotic. $R$. toxicus is obligately vectored and requires a successful nematode infestation before bacterial colonization of the plant and developing seed head can occur. Following seasonal rains, dormant nematodes and bacteria rehydrate and emerge from their overwintering galls. Juvenile nematodes migrate toward emerging grass seedlings and $R$. toxicus can adhere to the nematode cuticle and co-colonize the developing grass ovules (Price et al., 1979). As the nematodes complete their lifecycles by modifying nascent ovules into nematode galls, $R$. toxicus may outcompete the nematodes and transform the modified seed gall into a toxigenic bacterial gall (Price et al., 1979; Stynes and Bird, 1982). Both the nematode and bacterial galls are capable of persisting in extreme environments for decades until favorable environmental conditions arise (Murray et al., 2015). The complex, nematode-dependent lifecycle presents many challenges to studying $R$. toxicus. Moreover, molecular 
investigations are exceedingly difficult to conduct because $R$. toxicus is listed as a biological select agent, recalcitrant to genetic modification, and averse to tunicaminyluracil production in vitro (Payne and Cockrum, 1988).

Here, we investigated (i) if TGCs are unique to $R$. toxicus or present in other grass-associated Rathayibacter species and determined (ii) the prevalence and diversity of the TGC within Rathayibacter species. Genomic analyses of globally collected Rathayibacter species identified three previously unknown tunicaminyluracil-related gene clusters in $R$. iranicus, the undescribed South African Rathayibacter species 'woodii,' and the North American species, $R$. agropyri. The TGCs have high sequence similarity to the TGC-essential genes of $R$. toxicus and Streptomyces chartreusis.

\section{MATERIALS AND METHODS}

\section{Bacterial Strains, Growth Conditions, and DNA Extraction}

Rathayibacter species evaluated are listed in Table 1. Cultures were preserved in $15 \%$ glycerol and stored at $-80^{\circ} \mathrm{C}$ for long term storage. Depending upon the species, Rathayibacter strains were incubated for $3-6$ days at $25-28^{\circ} \mathrm{C}$ on modified YGM media (Sechler et al., 2017). The MasterPure Gram-Positive DNA Purification Kit (Epicentre, Madison, WI, United States) was used to extract genomic DNA according to the manufacturer's protocol, and the DNA was quantified with a Nanodrop-2000 (Thermo Fisher Scientific, Waltham, MA, United States).

\section{Genome Sequencing and Assembly}

Three sequencing platforms, 454 Junior (Roche, Basel, Switzerland), Illumina (Illumina, San Diego, CA, United States), and PacBio RSII (Pacific Biosciences, Menlo Park, CA, United States), were used to sequence Rathayibacter strains (Supplementary Table S1). For $R$. woodii FH236, R. iranicus FH6, and $R$. iranicus FH177, a shotgun DNA library was constructed for the 454 Junior according to the manufacturer's instructions, and three sequencing runs were performed. An additional PacBio sequencing library was prepared for $R$. iranicus FH6 and sequenced by the Genomics Lab at Washington State University. NGS DNA PCR-free libraries for R. agropyri strains and $R$. iranicus FH164 and FH176 were prepared according to the manufacturer's protocols and sequenced on an Illumina MiSeq by the Georgia Genomics and Bioinformatics Core at the University of Georgia. Sequence data was assembled using Lasergene Ngen v12.0 (DNAStar), PATRIC v3.5.41 (Wattam et al., 2017), or Pacific Bioscience's Hierarchical Genome-Assembly Process, as previously described (Savory et al., 2017; Sechler et al., 2017; Davis et al., 2018).

\section{Gene Annotation, Sequence Analysis, and Detection}

The putative tunicaminyluracil gene clusters were identified and manually annotated using a combination of programs, including antiSMASH (Weber et al., 2015), BLAST search tools (default settings with $R$. toxicus TGC queries) (Altschul et al., 1997), InterPro (Finn et al., 2017), and Artemis v17.0.1 (Rutherford et al., 2000). Sequence conservation between the Rathayibacter species tunicaminyluracil-related gene clusters was analyzed using the default TBLASTX settings with the Artemis Comparison Tool v17.0.1 (Rutherford et al., 2000; Carver et al., 2005). The tunicaminyluracil gene cluster schematics were constructed and annotated using Easyfig v2.2.4 (Sullivan et al., 2011). Percent amino acid identity relative to $R$. toxicus FH79 was calculated using Clustal $\Omega$ (Clustal2.1) at EMBL-EBI (Sievers et al., 2011; Li et al., 2015). Pairwise average nucleotide identities (ANI) were calculated using autoANI and methods previously described (Goris et al., 2007; Davis et al., 2016, 2018). Publicly available tunicaminyluracil gene cluster sequences for Rathayibacter and related Actinobacteria species were downloaded from NCBI in October of 2017 (Land et al., 2009;

TABLE 1 | Overview of the putative tunicaminyluracil gene clusters (TGC) evaluated in the current study.

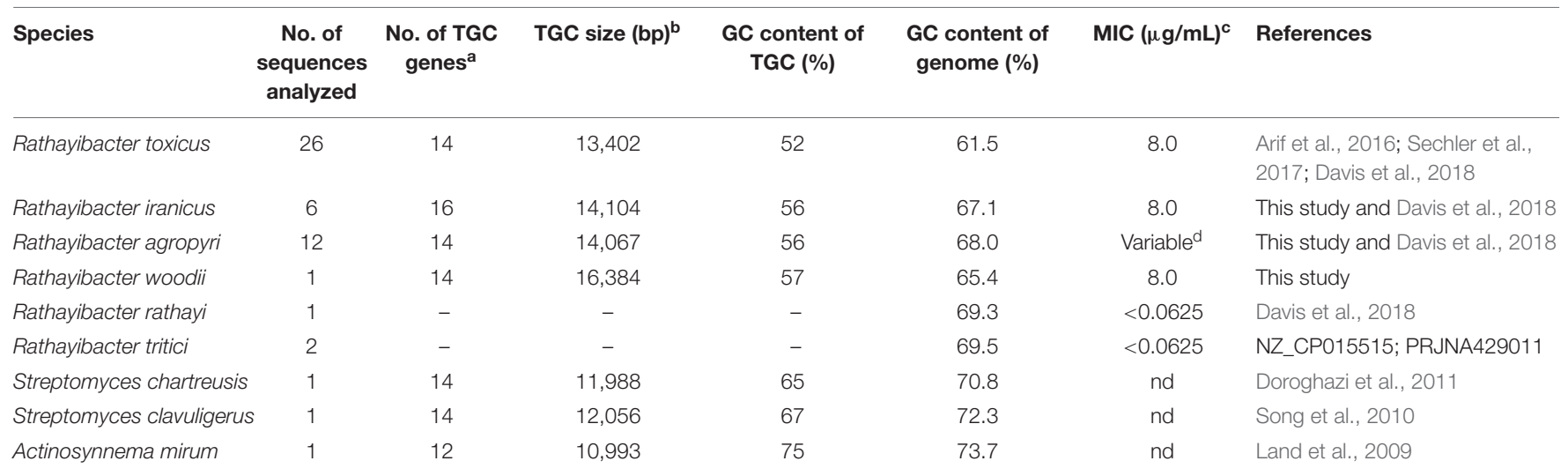

${ }^{a}$ The number of putative genes present in the identified tunicaminyluracil gene clusters. ${ }^{b}$ The TGC size is based on the reference strains, $R$. toxicus FH79 (Sechler et al.,

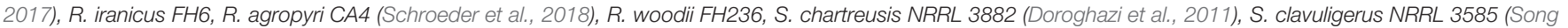

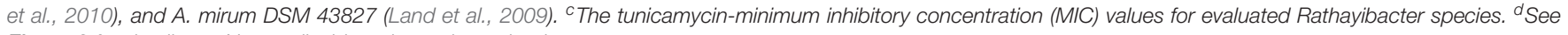
Figure 3 for details. -, Not applicable; nd, not determined. 
Song et al., 2010; Doroghazi et al., 2011; Sechler et al., 2017; Davis et al., 2018).

Actinobacteria sequences for the conserved reference genes (gyrB, dnaB, rpoB, recA, atpD, and 16S RNA genes) were identified based on protein or DNA homology to genes of $R$. toxicus. The full length DNA sequences were concatenated and aligned with Muscle in MEGA v7.0 (Kumar et al., 2016). A maximum likelihood phylogeny was estimated using W-IQ-TREE (Trifinopoulos et al., 2016) using the best-fit substitution model with branch support being assessed with the Shimodaira-Hasegawa-like approximate likelihood ratio (SH-aLRT) (Guindon et al., 2010) and Ultrafast Bootstrap Approximation tests (UFB) (Hoang et al., 2018) using 1000 bootstrap replicates for each method. Trees were visualized using FigTree v1.4.4 ${ }^{1}$. The same approach was used to construct phylogenetic trees of the putative tunicaminyluracil-associated genes (tunA-tunF, tunH-tunL).

MEGA v7.0, using Muscle and Clustal alignment default features, was used to assess the genetic diversity observed within the TGCs of $R$. toxicus, $R$. iranicus, and R. agropyri (Kumar et al., 2016). The predicted effects of missense mutations, among the TGC-conserved Rathayibacter genes (tunA-tunL), were predicted in silico with PROVEAN (Protein Variation Effect Analyzer) (Choi and Chan, 2015). If a missense mutation was predicted by PROVEAN to be deleterious, the effect of the mutation was analyzed using the program SIFT (Sorting Intolerant From Tolerant) (Vaser et al., 2016). The database for SIFT analyses consisted of amino acid sequences from Streptomyces chartreusis NRRL 3882, S. clavuligerus NRRL 3585, Actinosynnema mirum DSM 43827, R. toxicus FH79, R. toxicus FH232, and $R$. woodii FH236. A missense mutation was designated deleterious only if both algorithms predicted a deleterious mutation.

PCR was used to test for the presence of a TGC in strains of $R$. toxicus, $R$. iranicus, and $R$. woodii without associated genome sequences. Primers designed to amplify tunA, tunC, tunF were used (Supplementary Table S4). Amplification using EmeraldAmp MAX HS PCR Master Mix (Takara Bio Inc., Otsu, Shiga, Japan) or PrimeSTAR GXL DNA polymerase (Takara Bio Inc., Otsu, Shiga, Japan) was performed in an Applied Biosystems GeneAmp 9700 thermal cycler (Thermo Fisher Scientific, Waltham, MA, United States). Approximately $30 \mathrm{ng}$ of extracted total DNA was used per $25 \mu \mathrm{L}$ reaction with $0.2 \mu \mathrm{M}$ of each primer. PCR using EmeraldAmp was performed with the following parameters: initial preheat for $2 \mathrm{~min}$ at $98^{\circ} \mathrm{C} ; 32$ cycles at $98^{\circ} \mathrm{C}$ for $10 \mathrm{~s}$, a primer-pair-specific temperature for $20 \mathrm{~s}$ (Supplementary Table S4), and $72^{\circ} \mathrm{C}$ for $90 \mathrm{~s}$; a final extension at $72^{\circ} \mathrm{C}$ for $2 \mathrm{~min}$; and held at $10^{\circ} \mathrm{C}$. PCR using PrimeSTAR was performed as a two-step reaction with 32 cycles at $98^{\circ} \mathrm{C}$ for $10 \mathrm{~s}$ and $75^{\circ} \mathrm{C}$ for $10 \mathrm{~min}$. PCR products were electrophoresed on $1 \%$ GelGreen-stained $0.5 \mathrm{x}$ TAE agarose gels at $80 \mathrm{~V}$ for $45-60 \mathrm{~min}$.

\section{Tunicamycin Sensitivity Assays}

Differences in tunicamycin sensitivity were assessed with Streptomyces-produced tunicamycin (Sigma-Aldrich, St. Louis, MO, United States). Standardized methods for determining

${ }^{1}$ http://tree.bio.ed.ac.uk/software/figtree/ the minimum inhibitory concentration for tunicamycin were performed (Andrews and Andrews, 2001). Independent batches of tunicamycin were dissolved in alkaline water $(\mathrm{pH}>9.0)$ and prepared as twofold dilutions in 6-well Falcon tissue culture plates (Corning Inc., Corning, NY, United States) containing $3 \mathrm{~mL}$ of modified YGM media. Wells were inoculated with $3 \mu \mathrm{L}(1: 1000)$ of a fresh Rathayibacter culture $\left(\mathrm{OD}_{600}<1.0\right)$ and incubated on a rotary shaker at $28^{\circ} \mathrm{C}$. Each plate contained positive (no tunicamycin) and negative (media only) control wells. Atoxigenic Rathayibacter species consisted of four strains of $R$. rathayi and three strains of $R$. tritici. Toxigenic Rathayibacter species consisted of four strains of $R$. iranicus, three strains of $R$. toxicus, 12 strains of $R$. agropyri, and two strains of R. woodii. Growth was observed visually at 7 - and 14-days post inoculation. The entire experiment was repeated twice.

\section{RESULTS}

To determine if the TGC is unique to R. toxicus, we analyzed both previously and newly sequenced Rathayibacter genomes (Supplementary Table S1). Twenty-one globally collected Rathayibacter strains were previously sequenced, representing 18 strains of $R$. toxicus, 2 strains of $R$. iranicus, and one strain of $R$. agropyri (Sechler et al., 2017; Davis et al., 2018). To complement the previously sequenced genomes, a single isolate of $R$. woodii, $11 R$. agropyri strains, and an additional four $R$. iranicus strains were sequenced (Supplementary Table S1) (Davis et al., 2018).

\section{Rathayibacter woodii Represents a New Species Group in the Rathayibacter Genus}

Previous chemotaxonomic reports suggested that $R$. woodii is a distinct Rathayibacter species (Riley et al., 2004). Results from an Average Nucleotide Identity comparison and maximum likelihood (ML) phylogenetic analysis were consistent with the previous chemotaxonomic reports (Figure 1 and Supplementary Table S2). The phylogenetic analysis based on six conserved loci had similar topology to the whole-genome ML tree recently constructed for the Rathayibacter genera (Davis et al., 2018). All tested Rathayibacter species cluster together and clearly separate from the closely related genus Leifsonia and related Actinobacteria (Figure 1). Within the Rathayibacter clade, $R$. woodii is on a separate branch and appears most genetically similar to $R$. toxicus, as determined on the basis of strong bootstrap support (100\%) (Figure 1).

\section{Three Species of Rathayibacter Have Novel Tunicaminyluracil Biosynthetic Gene Clusters}

The $R$. toxicus TGC contains 14 genes, of which 13 genes (all except tunC) are predicted to comprise a single polycistronic operon (Figure 2) (Sechler et al., 2017). These TGC-associated genes and those of $S$. chartreusis were used as queries to search for homologs of tunicaminyluracil-related genes 


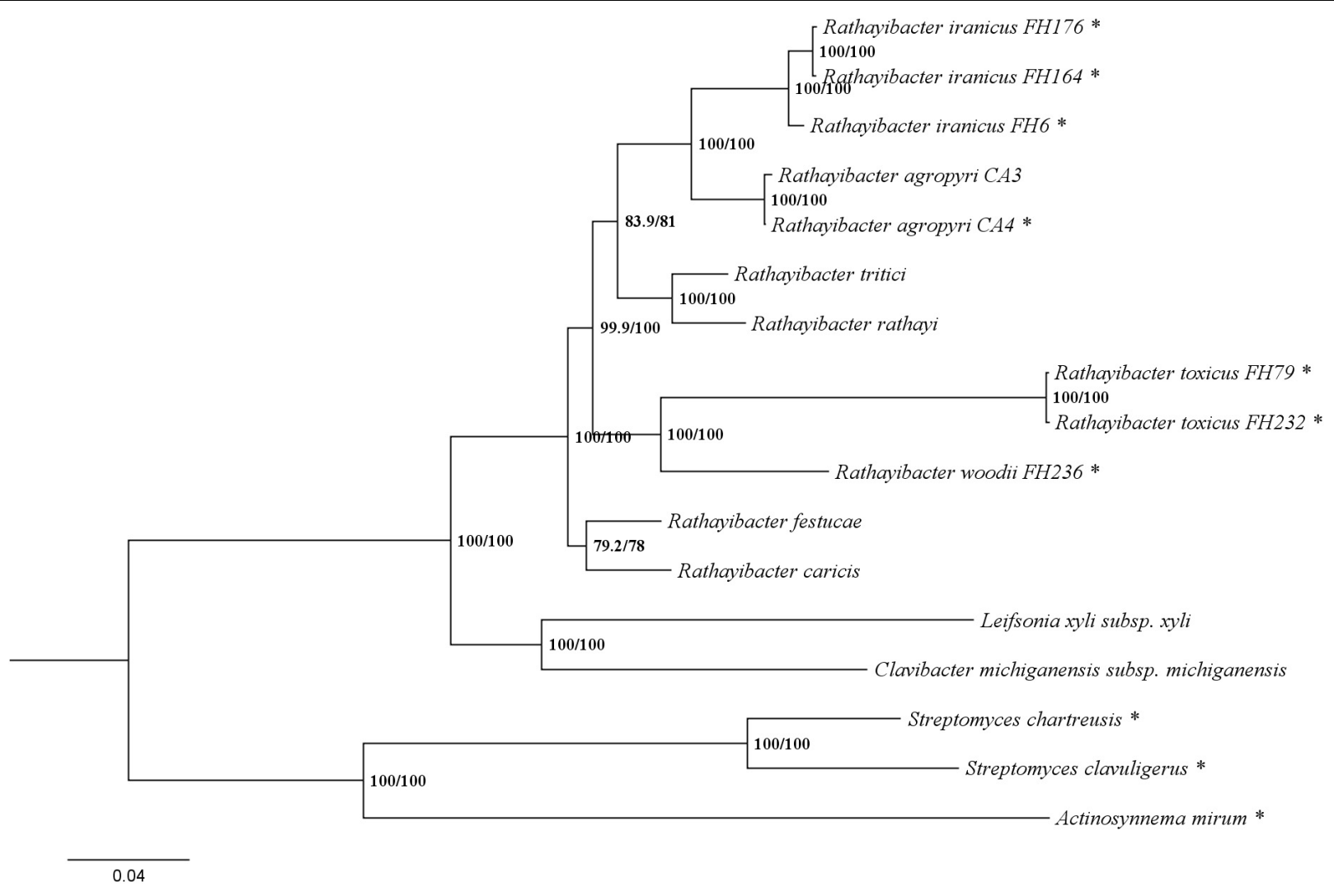

FIGURE 1 | Rathayibacter woodii is a distinct species in the Rathayibacter genus. The phylogeny is based on concatenated gyrB, dnaB, rpoB, recA, atpD, and $16 \mathrm{~S}$ rDNA nucleotide sequences from Rathayibacter and related Actinobacteria. The percentage of replicate trees in which the associated taxa clustered together are shown at the nodes: IQ-TREE SH-aLRT bootstrap support/Ultrafast bootstrap support. Actinobacteria with putative tunicaminyluracil gene clusters are designated with an asterisk.

in the newly sequenced Rathayibacter genomes. Three tunicaminyluracil-related biosynthetic gene clusters were identified in $R$. iranicus, $R$. woodii, and $R$. agropyri. Most genes necessary for tunicaminyluracil biosynthesis were conserved among the four Rathayibacter species, Streptomyces species, and Actinosynnema mirum, and unique genes were also present (Tables 1, 2). The TGCs of the four Rathayibacter species are similar in having lower GC-content relative to their respective genomes and having homologous genes essential for tunicaminyluracil biosynthesis (Table 1). No homologs of essential tunicaminyluracil-related genes were identified in other sequenced Rathayibacter species.

The TGCs of the other three species vary in gene order, direction, and total gene count relative to that of $R$. toxicus (Tables 1, 2 and Figure 2). The R. woodii-TGC is larger ( $\sim 16 \mathrm{~kb}$ in length) than the $R$. toxicus-TGC, likely a consequence of the insertion of transposase genes between an inverted tunC and the rest of the locus. $R$. woodii has homologs of the 13 genes present in the TGC of $R$. toxicus (tunA-tunL, tunP); the hypothetical $R$. toxicus gene tunO is replaced by an enoyl-CoA hydratase/isomerase gene (tunQ). The phospholipid phosphatase-encoding gene (tunL) of $R$. woodii is approximately double the length of tunL homologs in other Rathayibacter species and its translated sequence shares 30\% amino acid identity to the C-terminal region of the R. toxicus TunL; however, the $\mathrm{N}$-terminal region ( $\sim 318$ aa) lacks any conserved motifs (Table 2). In $R$. woodii there is an inversion of tun $G$ and $t u n H$, interrupting a locus that would otherwise have the potential to encode a single polycistronic message (Figure 2).

Rathayibacter iranicus possesses a similarly sized TGC ( $\sim 14 \mathrm{~kb}$ in length) to $R$. toxicus and has 16 possible genes (Table 1). Three of the hypothetical open reading frames (ORFs), tunS, tunT, and tunR, appear to be unique. However, TunT appears to be a truncated C-terminal variant of TunG, as it shares $47 \%$ amino acid identity. $R$. iranicus lacks tunG. TunR is predicted to encode a $4^{\prime}$-phosphopantetheinyl transferase and its gene $(t u n R)$ is located at the end of the locus.

The TGC of $R$. agropyri is most similar in gene sequence, composition, and order as the TGC of $R$. iranicus (Figure 2). $R$. agropyri lacks the histidine phosphatase gene (tunG) and possesses the $4^{\prime}$-phosphopantetheinyl transferase $($ tunR) gene at the terminal end of the locus. However, R. agropyri contrasts with other TGC-containing Rathayibacter species, in exhibiting a high degree of presence/absence polymorphisms of the TGC within the taxon. Eight strains are predicted to have complete TGCs. However, we could not identify a TGC locus in the 


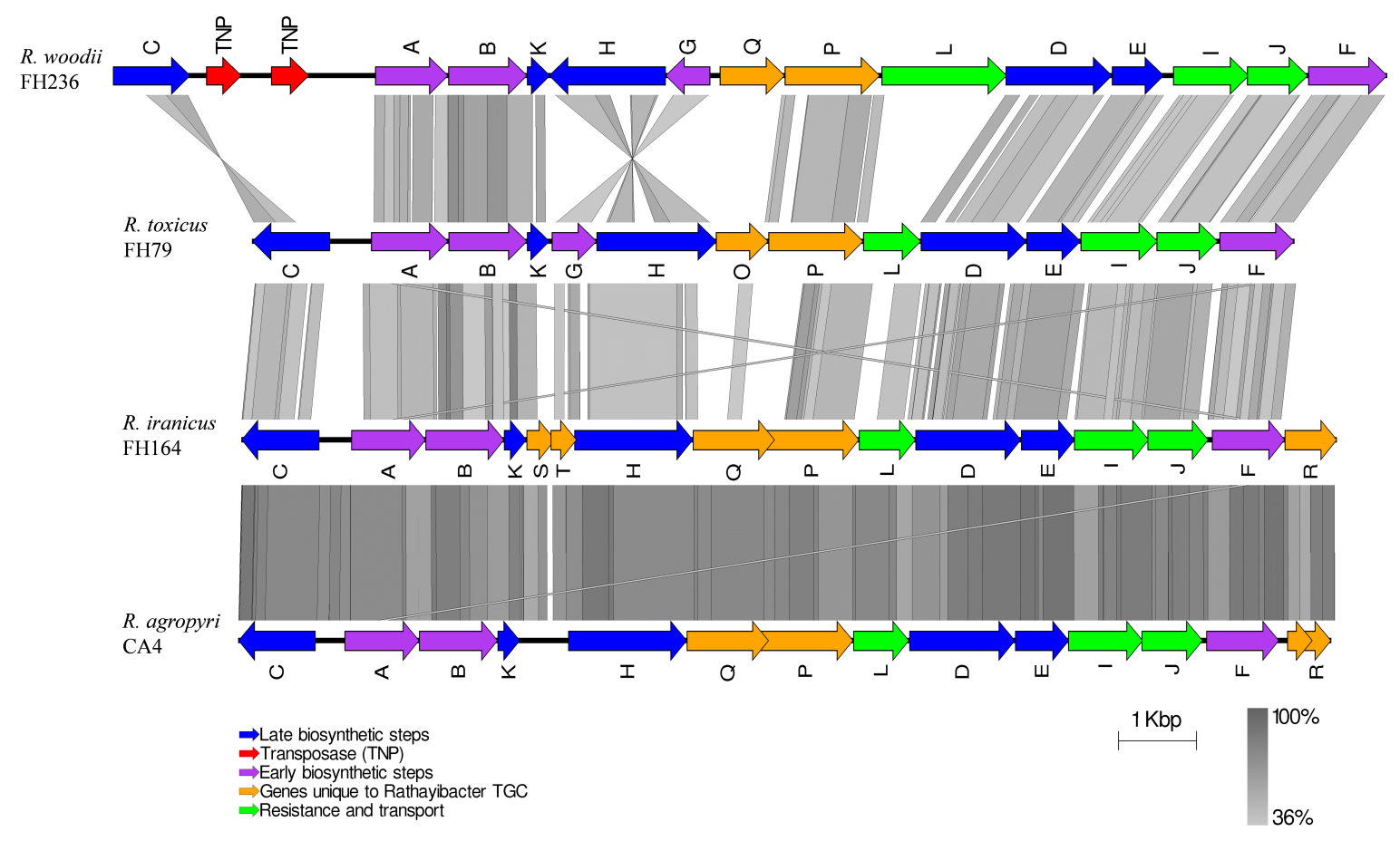

FIGURE 2 | Tunicaminyluracil-related gene cluster comparisons of Rathayibacter species. Microsynteny and sequence conservation between the tunicaminyluracil-related gene clusters for Rathayibacter toxicus FH79 (Sechler et al., 2017), R. iranicus FH164, R. woodii FH236, and R. agropyri CA4 (Schroeder et al., 2018). Predicted ORFs are shown in their respective orientation with alignment blocks corresponding to the level of sequence identity.

genome sequence of $R$. agropyri strain CA-49. Last, in strains CA-3, CA-47, CA-80, we could detect only incomplete TGCs that circumscribe complete coding sequences for tunI, tunJ, tunF, and tunR as well as fragmented sequences of tunA and tunC (Figure 3).

\section{Independent Horizontal Gene Transfer of the $R$. woodii TGC}

Despite the genetic relatedness of $R$. woodii to $R$. toxicus (Figure 1), the TGC of $R$. woodii is different from those of $R$. toxicus, $R$. iranicus, and $R$. agropyri (Figure 2). A phylogenetic analysis based on the concatenation of eleven TGC-conserved genes placed the TGCs from $R$. toxicus, $R$. iranicus, and $R$. agropyri into a clade with bootstrap support of $100 \%$ (Figure 4). The Eurasian $R$. iranicus isolates and the North American $R$. agropyri isolates appear to have highly conserved TGCs. However, the TGC of $R$. woodii is on a branch separate from $R$. toxicus, $R$. iranicus, $R$. agropyri, and all other characterized TGC-possessing Actinobacteria (Figure 4). The phylogeny of the conserved TGC is incongruent with the Rathayibacter genera phylogenetic tree, suggesting independent horizontal gene transfer of the $R$. woodii TGC. Further evidence of horizontal TGC transfers is the combination of a low GC content, relative to the genome, and flanking transposase genes (Table 1). Except for R. toxicus, all TGC-possessing Rathayibacter species have transposase-encoding genes downstream of tunC; and the recently isolated $R$. agropyri strain, CA-34, has upstream and downstream transposase genes flanking the TGC.

\section{Presence of Rare Regulatory Codons in the Rathayibacter TGC}

The overrepresentation of rare TTA leucine codons in Rathayibacter TGCs, relative to the rest of the genome, could be indicative of past horizontal gene transfer events and post-translational regulation, as in other Actinobacteria (Chandra and Chater, 2008; Bedhomme et al., 2019) (Table 3). Approximately $2.4 \%$ of $R$. toxicus leucine codons are represented by the rare TTA codon in the genome; however, within the TGC, the rare TTA codon represents $11 \%$ of all sites coding for leucine (Table 3). Similarly, $R$. iranicus, $R$. woodii, and $R$. agropyri have $<1 \%$ of rare TTA codons represented in their genomes, but between $4.2-5.7 \%$ within their respective TGCs. In contrast, Streptomyces species possess a similar percentage of rare TTA codons $(<1 \%)$ in both the TGC and genome (Table 3$)$.

\section{Non-synonymous Mutations Within the TGCs of $R$. toxicus and $R$. iranicus Are Not Predicted to Impact Protein Function}

The TGC is present in all 37 strains of $R$. toxicus and 23 strains of $R$. iranicus (Supplementary Table S1). Sequence analysis of the $R$. toxicus TGC revealed a total of 66 single nucleotide polymorphisms (SNPs) present within the tunicaminyluracil-associated genes, relative to FH79. A total of three $R$. toxicus-TGC haplotypes were identified between the 26 sequenced strains with most SNPs belonging to the TGC of R. toxicus FH100/232 (Table 4). Only 2 SNPs (tunB and tunD) 
TABLE 2 | Genes associated with the putative tunicaminyluracil-related gene clusters of Rathayibacter toxicus FH79 (Sechler et al., 2017 ), R. agropyri CA4 (Schroeder et al., 2018), R. iranicus FH164, R. woodii FH236, Streptomyces chartreusis 3882 (Doroghazi et al., 2011), and Actinosynnema mirum DSM 43827 (Land et al., 2009 ).

\begin{tabular}{|c|c|c|c|c|c|c|c|}
\hline \multirow[b]{2}{*}{ Gene $^{a}$} & \multirow[b]{2}{*}{ Description } & \multicolumn{6}{|c|}{ Protein length (aa) and\% amino acid identity relative to $R$. toxicus $\mathrm{FH} 79^{\mathrm{b}}$} \\
\hline & & R. toxicus & R. agropyri & R. iranicus & R. woodii & S. chartreusis & A. mirum \\
\hline $\operatorname{tun} A$ & Epimerase & 330 & $320(54 \%)$ & $320(53 \%)$ & $313(46 \%)$ & $321(42 \%)$ & $322(38 \%)$ \\
\hline $\operatorname{tun} B$ & Radical SAM & 337 & 337 (86\%) & 337 (84\%) & $338(71 \%)$ & $338(68 \%)$ & $340(67 \%)$ \\
\hline tunc & Acetyltransferase & 333 & $331(52 \%)$ & $333(51 \%)$ & $330(38 \%)$ & $318(28 \%)$ & $318(29 \%)$ \\
\hline tunD & Glycosyltransferase & 454 & $453(55 \%)$ & $453(55 \%)$ & $456(40 \%)$ & $472(37 \%)$ & $451(38 \%)$ \\
\hline tunE & $N$-deacetylase & 232 & $230(62 \%)$ & $230(62 \%)$ & $222(49 \%)$ & $234(42 \%)$ & $230(43 \%)$ \\
\hline $\operatorname{tunF}$ & Epimerase & 320 & $312(60 \%)$ & $312(60 \%)$ & $338(45 \%)$ & $327(35 \%)$ & $328(35 \%)$ \\
\hline $\operatorname{tun} G$ & Histidine phosphatase & 192 & - & - & 192 (36\%) & $203(31 \%)$ & $223(30 \%)$ \\
\hline tunH & Nucleotide pyrophosphatase & 515 & $509(50 \%)$ & 509 (48\%) & 499 (39\%) & $515(38 \%)$ & $510(37 \%)$ \\
\hline tunl & $A B C$ transporter & 330 & $320(49 \%)$ & $320(50 \%)$ & $324(34 \%)$ & $304(32 \%)$ & 302 (29\%) \\
\hline $\operatorname{tunJ}$ & ABC-2 transporter & 262 & $261(65 \%)$ & $261(64 \%)$ & $260(47 \%)$ & 262 (44\%) & $253(47 \%)$ \\
\hline tunk & Acyl carrier protein & 96 & $96(45 \%)$ & $96(44 \%)$ & $98(33 \%)$ & $81(30 \%)$ & $85(28 \%)$ \\
\hline tunL & Phospholipid phosphatase & 247 & $239(32 \%)$ & $243(31 \%)$ & $537(22 \%)$ & $229(22 \%)$ & 293 (23\%) \\
\hline tunM & Methyltransferase & - & - & - & - & 216 & - \\
\hline $\operatorname{tun} N$ & Pyrophosphatase & - & - & - & - & 152 & - \\
\hline tunO & Hypothetical protein & 224 & - & - & - & - & - \\
\hline $\operatorname{tun} P$ & Polyketide synthase & 407 & 408 (57\%) & 407 (58\%) & $408(48 \%)$ & - & - \\
\hline $\operatorname{tun} Q$ & Enoyl-CoA hydratase/isomerase & - & 351 & 351 & 279 & - & - \\
\hline $\operatorname{tun} R$ & $4^{\prime}$-phosphopantetheinyl transferase & - & 224 & 224 & - & - & - \\
\hline tuns & Hypothetical protein & - & - & 122 & - & - & - \\
\hline tunT & Hypothetical protein & - & - & 111 & - & - & - \\
\hline
\end{tabular}

${ }^{a}$ Genes in bold text are essential for tunicamycin biosynthesis and immunity in Streptomyces chartreusis (Widdick et al., 2018). b_, Absence of gene.

differentiated the emerging $R$. toxicus population, SA03-04, from the type strain, $R$. toxicus FH79. Comparing the dominant $R$. toxicus TGC haplotype to $R$. toxicus FH100/232 revealed numerous polymorphisms, non-synonymous mutations, and insertions/deletions (INDELs) (Table 4). A six nucleotide INDEL was present at the $3^{\prime}$ end of $t u n D$, resulting in a premature stop codon and subsequent truncation by two amino acids. The INDEL further modified the downstream gene $t u n E$ via the addition of two amino acids to the $\mathrm{N}$-terminus (Table 4). Within $R$. toxicus, tunA was the most polymorphic gene with 21 SNPs corresponding to $2.1 \%$ variation. No SNPs were observed in tunF, tunJ, and $\operatorname{tunK}$. With the exception of the INDEL, all remaining 35 non-synonymous mutations resulted in missense mutations that were predicted in silico by PROVEAN software to not affect protein function (Table 4) (Choi and Chan, 2015).

Sequence data from six diverse $R$. iranicus strains collected from Iran and Turkey revealed five unique TGC haplotypes, corresponding to approximately 600 SNPs (Table 4). The TGC of $R$. iranicus type strain FH6 differed from $R$. iranicus FH154, FH157, and FH177 by only 1-2 SNPs; however, most TGCassociated SNPs were attributed to $R$. iranicus strains FH164 and FH176. A 15 nucleotide INDEL at the beginning of tunA was identified in both $R$. iranicus FH164 and FH176 and is predicted to result in a truncated protein (Table 4). $R$. iranicus FH6, FH154, FH157, and FH177 each have a premature stop codon, predicted to truncate TunT 22 amino acids from the start position. An additional three nucleotide INDEL in tunT is present in R. iranicus FH164 and FH176, resulting in the deletion of a codon for tryptophan (W77). The sequence diversity observed in the TGC of R. iranicus FH164 and FH176 were mirrored in the rest of the genome, consistently separating R. iranicus FH164 and FH176 from the R. iranicus type strain FH6 (Figures 1, 4). A total of 223 non-synonymous mutations were identified within the $R$. iranicus TGC, but the missense mutations were predicted to be tolerated on the basis of in silico analysis (Table 4) (Choi and Chan, 2015; Vaser et al., 2016). A single amino acid substitution in TunB (I48T) of $R$. iranicus FH164 and FH176 was predicted by PROVEAN, but not SIFT, to affect protein function (Table 4).

\section{Genetic Variability Within R. agropyri Has Resulted in Strains Having Complete, Partial, or No TGC}

Sequencing an additional $11 R$. agropyri strains, collected from the Western United States, revealed eight strains with a complete TGC, three strains with TGC remnants, and a single strain (CA-49) that had no evidence of a TGC (Figure 3). The presence of a TGC does not appear to be spatially or temporally correlated, with $R$. agropyri strains collected between 1945 and 2013 possessing complete TGCs (Figure 3 and Supplementary Table S1). Among the eight strains that possess a TGC, a total of 6 unique haplotypes were identified with 359 SNPs and a single 901 bp transposase in tunR of strain CA-34. The 4'-phosphopantetheinyl transferase (tunR) gene has the highest percentage of mutations, which resulted in frame shifts, 


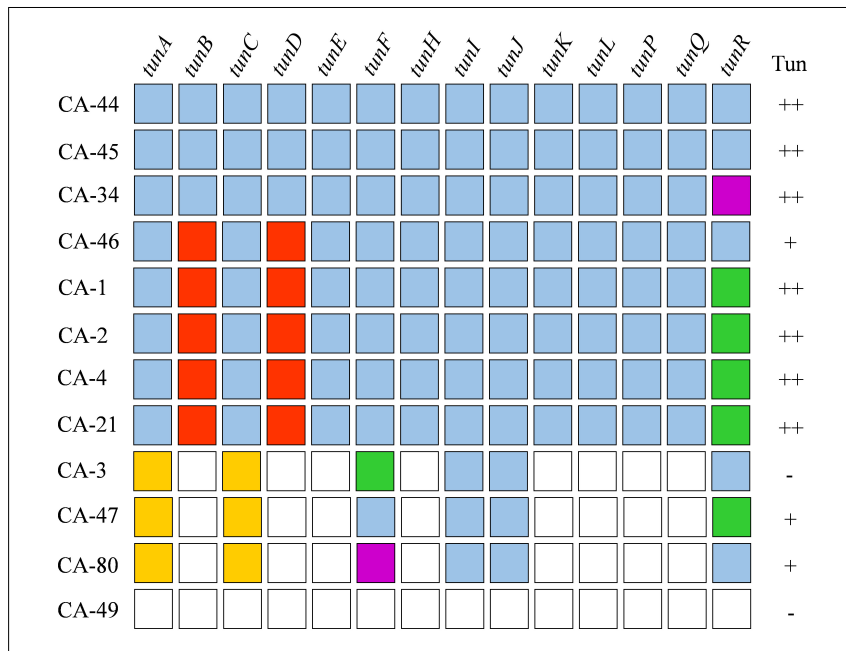

FIGURE 3 | Genetic variability of tunicaminyluracil-related gene clusters between Rathayibacter agropyri strains. Tunicaminyluracil-related genes are listed across the top, $R$. agropyri strains are listed on the left side, and tunicamycin tolerance is denoted in the right most column. Rathayibacter agropyri tunicaminyluracil-associated genes are displayed in alphabetical order: gene is present (blue), gene is absent (white), gene is partially present (gold), a frameshift mutation is present (green), a mutation is predicted to affect protein function (red), and a transposon insertion (purple). Tunicamycin tolerance was assessed where strains showed no resistance $(-)$, growth at $1 \mu \mathrm{g} / \mathrm{ml}(+)$, or growth above $1 \mu \mathrm{g} / \mathrm{ml}(++)$.

nonsense mutations, or INDELS in five of the eight $R$. agropyri strains (Table 4 and Figure 3). A total of 158 non-synonymous mutations were identified within the $R$. agropyri TGC with most missense mutations predicted to be tolerated in silico (Choi and Chan, 2015; Vaser et al., 2016). However, the single amino acid substitutions in TunB (D282Y) and TunD (G30R) of R. agropyri strains CA-1, CA-2, CA-4, CA-21, and CA-46 were predicted to affect protein function in both PROVEAN and SIFT analyses (Table 4 and Figure 3). An additional amino acid substitution in TunH (R247C) of $R$. agropyri strains CA-1, CA-2, CA-4, CA-21, and CA-46 was predicted by PROVEAN, but not SIFT, to affect protein function (Table 4).

The four $R$. agropyri strains that either lacked or had remnants of a TGC were isolated from samples collected between 1950 and 2014 from Idaho, Colorado, or Washington (Supplementary Table S1). Complete or partial TGCs were in the same chromosomal position with flanking ORFs, except for strain CA-49, which lacked a TGC. Rathayibacter agropyri strains CA-3, CA-47, and CA-80 had complete tunI and tunJ ORFs and approximately 5 and 25 amino acids of the N-terminus of TunA and TunC, respectively. tunF was complete in CA-47 but contained nonsense mutations and transposon insertions in CA-3 and CA-80, respectively. tunR was complete in CA-3 and CA-80, while CA-47 contained an early nonsense mutation.

\section{Rathayibacter Strains With a TGC Locus Are Tolerant to Exogenous Tunicamycin}

Tolerance by atoxigenic and toxigenic Rathayibacter species to tunicamycin was evaluated to determine if the presence or absence of the TGC influenced tunicamycin sensitivity. Atoxigenic strains of $R$. rathayi and $R$. tritici were highly sensitive to externally applied tunicamycin with a minimum inhibitory concentration (MIC) value $<0.0625 \mu \mathrm{g} / \mathrm{mL}$ (Table 1 and Supplementary Table S3). In contrast, putatively toxigenic $R$. toxicus, $R$. iranicus, and $R$. woodii, were each tolerant, with MIC values of $8.0 \mu \mathrm{g} / \mathrm{mL}$ to externally applied tunicamycin (Table 1 and Supplementary Table S3). R. agropyri strains showed a range of sensitivity from $<0.0625$ to $8.0 \mu \mathrm{g} / \mathrm{mL}$ with sensitivity correlated to the absence of a complete TGC. No bacterial growth was observed in the negative control wells.

\section{DISCUSSION}

The distribution and conservation of tunicaminyluracil gene clusters within the nematode-vectored, grass-associated Rathayibacter genera has not been previously investigated; and tunicaminyluracil biosynthesis has been reported in only a handful of soil-associated bacterial species (Doroghazi et al., 2011). Therefore, genomic analyses were performed on available toxigenic and atoxigenic Rathayibacter species isolated from diverse geographic locations to determine if putative TGCs were conserved in this plant pathogenic taxon. In this study, we identified novel tunicaminyluracil-related gene clusters in three suspected toxigenic Rathayibacter species that infect wheat and grasses.

The first confirmed appearance of $R$. toxicus-like poisoning outside of Australia was documented in the Western Cape Province of South Africa in 1980 (Schneider, 1981). Schneider (1981) identified a Rathayibacter species in contaminated fodder that was responsible for livestock poisonings and quickly presumed it to be $R$. toxicus, although the identity of the bacterial species was never confirmed. Based on our results, it is plausible that the South African livestock poisonings were caused by an endemic toxigenic Rathayibacter species, such as $R$. woodii, as opposed to a foreign $R$. toxicus strain. Numerous nematode and $R$. woodii bacterial galls were isolated in the same Western Cape Province where the previous suspected R. toxicus-like poisonings occurred (Schneider, 1981; Riley and Swart, 2004; Grewar et al., 2009). R. woodii was isolated from dune grass (Ehrharta villosa var. villosa) in association with the leaf gall nematode, Anguina woodi (Riley et al., 2004; Riley and Swart, 2004). In contrast, Schneider (1981) associated the isolated toxigenic Rathayibacter species with Lolium species seed and the seed gall nematode Anguina agrostis. However, numerous studies have demonstrated that Rathayibacter grasshost range is determined by the nematode vector and not the bacterium, with $R$. toxicus being able to colonize multiple grass and Anguina species (Edgar et al., 1982; Riley and McKay, 1990, 1991; Riley et al., 2001). Future research will be needed to evaluate the ability of $R$. woodii to attach to the cuticle of other Anguina species.

Genetically similar tunicaminyluracil-related gene clusters were also identified in the geographically separated populations of $R$. iranicus and $R$. agropyri. $R$. iranicus has only been identified in Iran and Turkey and causes a gumming disease of wheat 


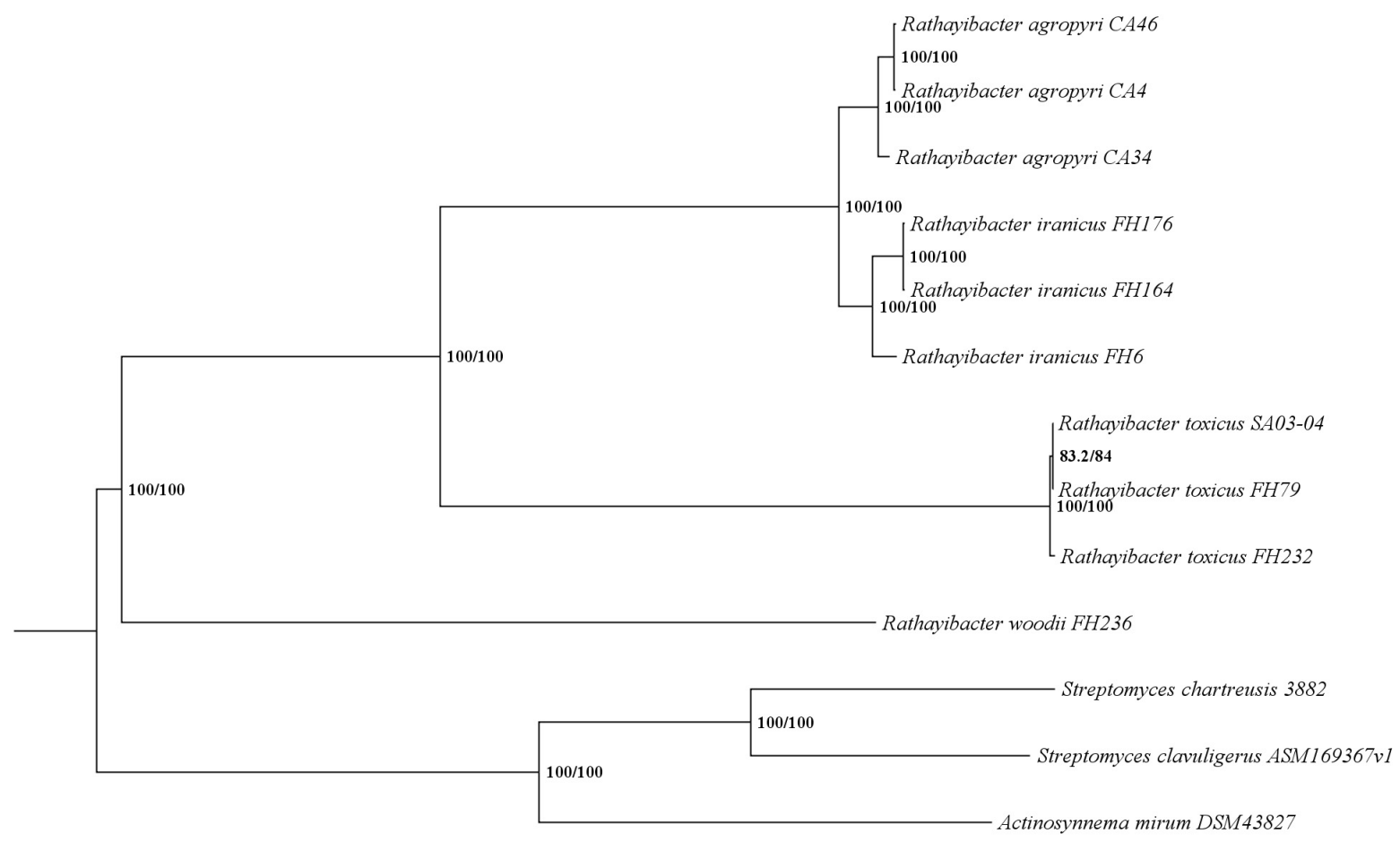

0.08

FIGURE 4 | The tunicaminyluracil-related gene cluster of Rathayibacter woodii is distinct from associated Actinobacteria. The phylogeny is based on concatenated tunicaminyluracil-related genes (tunA-tunL), with the exception of tunG due to the lack of conservation between species. The percentage of replicate trees in which the associated taxa clustered together are shown at the nodes: IQ-TREE SH-aLRT bootstrap support/Ultrafast bootstrap support.

similar to atoxigenic $R$. tritici (Bird, 1981; Postnikova et al., 2009; Fattah and Al-Assas, 2010). No supporting literature has described $R$. toxicus-like poisonings of livestock in Iran or Turkey, but wheat seed is rarely utilized as a food source for livestock. In contrast, historical accounts of livestock poisonings, associated with fodder contaminated with nematode galls, were documented in Oregon during the mid-twentieth century (Haag, 1943; Shaw and Muth, 1949; Galloway, 1961; Jensen, 1961).

The TGCs of $R$. iranicus and $R$. agropyri both lack the histidine phosphatase gene tunG. In place of tun $G, R$. iranicus has two hypothetical ORFs, with one of these putative genes (tunT) predicted to encode a truncated protein with homology to the C-terminal portion of TunG. However, the accumulation of mutations in tunT across diverse $R$. iranicus strains, and the lack of a conserved histidine phosphatase catalytic core, suggests that tunT may be a non-functional remnant of a histidine phosphatase. It remains unknown if $R$. iranicus or $R$. agropyri synthesize tunicaminyluracil, but Widdick et al. (2018) determined that just six genes (tunABCDEH) are essential for tunicamycin biosynthesis in S. chartreusis, with tunI and tunJ being required for immunity (Widdick et al., 2018). The remaining non-essential TGC-associated genes (tunFGKL) appear redundant with homologs involved in S. chartreusis primary metabolism, but may allow for proper stoichiometric mixtures at the initial stages of tunicamycin biosynthesis (Widdick et al., 2018).
Environmental factors that trigger the synthesis of tunicaminyluracil antibiotics in Rathayibacter species are unknown, and in-field production appears to be sporadic in the case of $R$. toxicus infections (Kowalski et al., 2007). The inconsistent production of tunicaminyluracil, both in vitro and in vivo, could be due to a variety of complex interactions, but it does not appear to be a result of $R$. toxicus strains lacking a functional TGC. The TGC was conserved in all strains of $R$. toxicus, $R$. woodii, and $R$. iranicus, and mutations were not predicted to disrupt protein function. In contrast, $R$. agropyri genotypes were highly diverse with strains having complete, partial, or missing TGCs. The accumulation of mutations predicted to impact protein function in TunB and TunD were also prevalent in $R$. agropyri. Of the $12 R$. agropyri strains, only three strains, CA-44, CA-45, and CA-34, have all the essential genes (without mutations) necessary for tunicaminyluracil production. Interestingly, $R$. agropyri CA-45 was collected from Oregon in 1950 during the state's reported $R$. toxicuslike poisoning events. Similarly, strains CA-44, CA-46, CA-2, CA-47, and CA-49 were collected in 1950 from nearby states, but either lacked or had diverse TGC loci. Recently collected $R$. agropyri isolates (CA-34, CA-21, and CA-80) possess TGCs that mirror the diversity observed in strains collected during the mid-20th century, with $R$. agropyri CA-34 possessing all essential tunicaminyluracil genes. The diversity of TGC sequences in $R$. agropyri genotypes could be one explanation for why 
TABLE 3 | The overrepresentation of rare TTA leucine codons within the tunicaminyluracil biosynthetic gene clusters of putatively toxigenic Rathayibacter and Streptomyces species.

\begin{tabular}{|c|c|c|c|c|c|c|}
\hline \multirow[b]{2}{*}{ Gene } & \multicolumn{6}{|c|}{ Number of rare TTA codons ( $\%$ of total Leu)* } \\
\hline & R. toxicus FH79 & R. iranicus FH6 & R. woodii FH236 & R. agropyri CA34 & S. clavuligerus 3585 & S. chartreusis 3882 \\
\hline tunA & $3(13.6)$ & $2(7.4)$ & $1(3.2)$ & $1(3.8)$ & $0(0.0)$ & $3(8.8)$ \\
\hline $\operatorname{tun} B$ & $6(16.7)$ & $2(5.4)$ & $0(0.0)$ & $3(8.1)$ & $0(0.0)$ & $0(0.0)$ \\
\hline tunC & $4(13.8)$ & $3(10.0)$ & $0(0.0)$ & $3(10.7)$ & $0(0.0)$ & $0(0.0)$ \\
\hline $\operatorname{tun} D$ & $6(11.5)$ & $2(4.0)$ & $3(5.4)$ & $2(3.9)$ & $0(0.0)$ & $0(0.0)$ \\
\hline tunE & $2(9.1)$ & $0(0.0)$ & $1(7.7)$ & $0(0.0)$ & $0(0.0)$ & $0(0.0)$ \\
\hline tunF & $2(9.5)$ & $1(3.6)$ & $0(0.0)$ & $1(3.7)$ & $0(0.0)$ & $0(0.0)$ \\
\hline $\operatorname{tun} G$ & $1(5.9)$ & - & $2(10.5)$ & - & $0(0.0)$ & $0(0.0)$ \\
\hline $\operatorname{tunH}$ & $6(12.5)$ & $3(6.5)$ & 2 (3.9) & $4(8.3)$ & $0(0.0)$ & $0(0.0)$ \\
\hline tunl & $4(11.4)$ & $0(0.0)$ & $3(7.5)$ & $1(2.6)$ & $0(0.0)$ & $0(0.0)$ \\
\hline tuns & $4(10.3)$ & $1(2.6)$ & $0(0.0)$ & $2(5.1)$ & $0(0.0)$ & $0(0.0)$ \\
\hline tunk & $0(0.0)$ & $0(0.0)$ & $1(9.1)$ & $0(0.0)$ & $0(0.0)$ & $0(0.0)$ \\
\hline tunL & $2(11.1)$ & $2(8.0)$ & $3(4.7)$ & $2(8.0)$ & $0(0.0)$ & $0(0.0)$ \\
\hline tunM & - & - & - & - & $1(3.6)$ & $1(4.0)$ \\
\hline $\operatorname{tun} N$ & - & - & - & - & $0(0.0)$ & $0(0.0)$ \\
\hline tunO & $1(5.6)$ & - & - & - & - & - \\
\hline tunP & 3 (12.0) & $0(0.0)$ & 1 (2.9) & $0(0.0)$ & - & - \\
\hline $\operatorname{tun} Q$ & - & $3(8.3)$ & 3 (8.3) & $5(13.2)$ & - & - \\
\hline tunR & - & $0(0.0)$ & - & - & - & - \\
\hline tuns & - & 1 (12.5) & - & - & - & - \\
\hline tunT & - & $0(0.0)$ & - & - & - & - \\
\hline TGC Total & $44(11.2)$ & $20(4.5)$ & $20(4.2)$ & $24(5.7)$ & $1(0.2)$ & $4(0.9)$ \\
\hline Genome Total & $1619(2.4)$ & $457(0.5)$ & $593(0.7)$ & $359(0.4)$ & $172(0.1)$ & Not sequenced \\
\hline
\end{tabular}

*-, absence of gene.

widespread livestock toxicosis events are not reported in the United States as they are in Australia.

There are three $R$. agropyri strains with partial TGCs: CA3, CA-47, and CA-80. The only two genes present in all three strains, tunI and tunJ, are the two required for immunity in S. chartreusis (Widdick et al., 2018). However, the requirements for full immunity to exogenous tunicamycin appear to be more complex in $R$. agropyri. None of these three strains grow at as high concentrations of tunicamycin as many of the strains with complete TGCs (Figure 3) and CA-3 exhibits no immunity to tunicamycin despite full-length copies of tunI and tunJ. Therfore, it is likely that additional genes, either in the TGC or elsewhere in the genome, contribute to full immunity in $R$. agropyri. Never the less, it is possible that the partial immunity given by tunI and tunJ confers a selective advantage to R. agropyri.

The low GC-content, overrepresentation of rare leucine codons, nearby transposase genes, and incongruence of phylogenetic trees strongly suggest that the TGC was horizontally acquired in the Rathayibacter genera, with likely at least two independent genetic transfer events. Although the origin of the $R$. woodii TGC remains unknown, it appears to be from a source that is different than the donor to $R$. toxicus. The TGC of $R$. woodii possesses the complete suite of tunicaminyluracil-related genes but is different in structure. Moreover, the putative TGC of $R$. woodii does not cluster with $R$. toxicus, despite the close genetic distance between the two species. While there are additional Streptomyces and Actinosynnema that contain TGCs closely related to the ones included in our analyses, there are no other putative TGCs in available bacterial genome sequences. Therefore, it is difficult to speculate on the origin of any of the Rathayibacter TGCs.

The presence of the TGC within multiple Rathayibacter species, the prevalence of the TGC locus among strains evaluated, the conservation and homology of tunicaminyluracil-essential genes, the increased tolerance to exogenous tunicamycin, and the historic reports of livestock poisonings, all suggest that these species possess(ed) functional tunicaminyluracil-related gene clusters. However, it is challenging to demonstrate that these Rathayibacter species synthesize biologically active tunicaminyluracil. The biological/environmental triggers that initiate tunicaminyluracil production in vitro are unknown and could differ among the species. Payne and Cockrum (1988) were intermittently able to induce in vitro production of tunicaminyluracil with $R$. toxicus, but required fresh field isolates, the process was highly strain specific, and tunicaminyluracil production was rapidly lost in vitro with successive subculturing (Payne and Cockrum, 1988). In fact, successful in vitro tunicaminyluracil production has only been consistently demonstrated within the Streptomyces genera, in which Streptomyces species are induced to synthesize tunicamycin under extended anaerobic conditions (Chen et al., 2010). Due to these limitations, tolerance to exogenous 
TABLE 4 | Genetic variation of the tunicaminyluracil biosynthetic gene cluster in sequenced Rathayibacter toxicus, R. iranicus, and R. agropyri strains, and their predicted impact to protein function.

\begin{tabular}{|c|c|c|c|c|c|c|c|c|}
\hline Gene & $\begin{array}{c}\text { Gene size } \\
\text { (bp) }{ }^{\mathrm{a}}\end{array}$ & $\begin{array}{l}\text { No. of } \\
\text { strains }\end{array}$ & $\begin{array}{c}\text { No. of } \\
\text { haplotypes }\end{array}$ & $\begin{array}{l}\text { No. (\%) of } \\
\text { polymorphic } \\
\text { sites }\end{array}$ & $\begin{array}{l}\text { No. of INDELs } \\
(\mathbf{b p})^{\mathrm{b}}\end{array}$ & $\begin{array}{c}\text { No. of } \\
\text { non-synonymous } \\
\text { mutations }^{c}\end{array}$ & $\begin{array}{l}\text { Type of } \\
\text { non-synonymous } \\
\text { mutation }\end{array}$ & $\begin{array}{l}\text { Predicted mutation } \\
\text { tolerated }^{\mathrm{d}}\end{array}$ \\
\hline \multicolumn{9}{|c|}{ R. toxicus } \\
\hline tunA & 993 & 26 & 2 & $21(2.1 \%)$ & - & 8 & Missense & Neutral \\
\hline $\operatorname{tun} B$ & 1014 & 26 & 3 & $4(0.4 \%)$ & - & 1 & Missense & Neutral \\
\hline $\operatorname{tun} C$ & 1002 & 26 & 2 & $8(0.8 \%)$ & - & 2 & Missense & Neutral \\
\hline $\operatorname{tun} D$ & 1365 & 26 & 3 & $5(0.4 \%)$ & 1 (6 bp) & 3 & Nonsense/Missense & Neutral \\
\hline tunE & 699 & 26 & 2 & $11(1.6 \%)$ & 1 (6 bp) & 4 & Missense & Neutral \\
\hline tunF & 963 & 26 & 2 & $0(0.0 \%)$ & - & 0 & - & - \\
\hline $\operatorname{tun} G$ & 579 & 26 & 2 & $1(0.2 \%)$ & - & 0 & - & - \\
\hline tunH & 1548 & 26 & 2 & $6(0.4 \%)$ & - & 4 & Missense & Neutral \\
\hline tunl & 993 & 26 & 2 & $6(0.6 \%)$ & - & 5 & Missense & Neutral \\
\hline tunJ & 789 & 26 & 2 & $0(0.0 \%)$ & - & 0 & - & - \\
\hline tunk & 291 & 26 & 2 & $0(0.0 \%)$ & - & 0 & - & - \\
\hline tunL & 744 & 26 & 2 & $1(0.1 \%)$ & - & 1 & Missense & Neutral \\
\hline tuno & 675 & 26 & 2 & 10 (1.5\%) & - & 6 & Missense & nd \\
\hline tunP & 1224 & 26 & 2 & 1 (0.1\%) & - & 1 & Missense & nd \\
\hline \multicolumn{9}{|c|}{ R. iranicus } \\
\hline $\operatorname{tun} A$ & 978 & 6 & 2 & $41(4.3 \%)$ & 1 (15 bp) & 12 & Missense & Neutral \\
\hline $\operatorname{tun} B$ & 1014 & 6 & 3 & $42(4.1 \%)$ & - & 12 & Missense & Neutral* \\
\hline $\operatorname{tun} C$ & 1002 & 6 & 3 & $54(5.4 \%)$ & - & 20 & Missense & Neutral \\
\hline tunD & 1362 & 6 & 3 & 51 (3.7\%) & - & 20 & Missense & Neutral \\
\hline tunE & 693 & 6 & 3 & 16 (2.3\%) & - & 2 & Missense & Neutral \\
\hline tunF & 939 & 6 & 3 & 30 (3.2\%) & - & 11 & Missense & Neutral \\
\hline tunH & 1530 & 6 & 3 & 76 (5.0\%) & - & 36 & Missense & Neutral \\
\hline tunl & 963 & 6 & 4 & 31 (3.2\%) & - & 14 & Missense & Neutral \\
\hline tunJ & 786 & 6 & 3 & 27 (3.4\%) & - & 7 & Missense & Neutral \\
\hline tunK & 291 & 6 & 2 & 24 (8.2\%) & - & 11 & Missense & Neutral \\
\hline tunL & 732 & 6 & 3 & 25 (3.4\%) & - & 15 & Missense & Neutral \\
\hline tunP & 1224 & 6 & 3 & 32 (2.6\%) & - & 8 & Missense & nd \\
\hline $\operatorname{tun} Q$ & 1056 & 6 & 2 & 31 (2.9\%) & - & 15 & Missense & nd \\
\hline tunR & 675 & 6 & 3 & $20(3.0 \%)$ & - & 11 & Missense & nd \\
\hline tuns & 369 & 6 & 2 & 41 (11.1\%) & - & 26 & Missense & nd \\
\hline tunt & 213 & 6 & 2 & $5(2.3 \%)$ & 1 (3 bp) & 3 & Nonsense/Missense & nd \\
\hline \multicolumn{9}{|c|}{ R. agropyri } \\
\hline $\operatorname{tun} A$ & 963 & 8 & 5 & 23 (2.4\%) & - & 7 & Missense & Neutral \\
\hline $\operatorname{tun} B$ & 1014 & 8 & 4 & $25(2.5 \%)$ & - & 7 & Missense & Deleterious \\
\hline $\operatorname{tun} C$ & 996 & 8 & 4 & $21(2.1 \%)$ & - & 7 & Missense & Neutral \\
\hline $\operatorname{tun} D$ & 1362 & 8 & 6 & $29(2.1 \%)$ & - & 13 & Missense & Deleterious \\
\hline tunE & 693 & 8 & 6 & $14(2.0 \%)$ & - & 4 & Missense & Neutral \\
\hline tunF & 939 & 8 & 5 & 25 (2.7\%) & - & 13 & Missense & Neutral \\
\hline $\operatorname{tunH}$ & 1530 & 8 & 5 & 52 (3.4\%) & - & 22 & Missense & Neutral* \\
\hline tunl & 963 & 8 & 6 & 38 (3.9\%) & - & 15 & Missense & Neutral \\
\hline tunJ & 786 & 8 & 4 & 16 (2.0\%) & - & 3 & Missense & Neutral \\
\hline tunk & 291 & 8 & 4 & $8(2.7 \%)$ & - & 5 & Missense & Neutral \\
\hline tunL & 720 & 8 & 5 & $15(2.1 \%)$ & 1 (3 bp) & 8 & Missense & Neutral \\
\hline tunP & 1227 & 8 & 6 & 22 (1.8\%) & - & 9 & Missense & nd \\
\hline $\operatorname{tun} Q$ & 1056 & 8 & 6 & 24 (2.3\%) & - & 12 & Missense & nd \\
\hline tunR & 675 & 8 & 6 & $50(7.4 \%)$ & 2 (1 bp) & 33 & Nonsense/Missense & nd \\
\hline
\end{tabular}

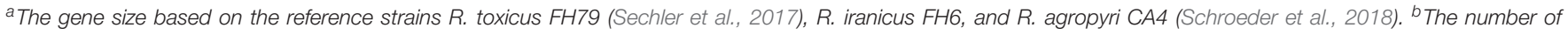

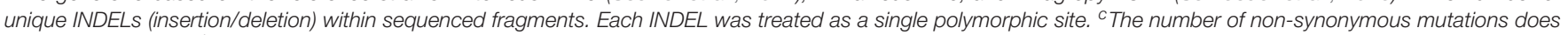

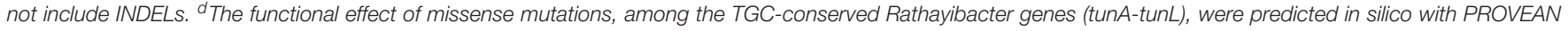

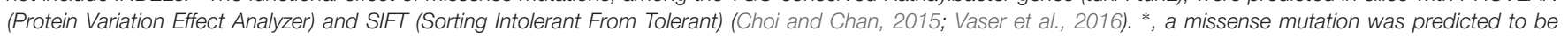
deleterious with PROVEAN, but tolerated with SIFT; nd, not determined due to the lack of adequate reference sequences. 
tunicamycin was used as a partial proxy for the TGCs functionality in Rathayibacter species. The genes required for tunicamycin immunity appear to be functional since TGCcontaining Rathayibacter species were able to tolerate exogenous applications of tunicamycin, in contrast to atoxigenic species. Interestingly, the newly described TGCs do not appear to possess any regulatory genes, similar to $S$. chartreusis and $R$. toxicus (Wyszynski et al., 2010; Sechler et al., 2017). However, tunicaminyluracil production in $R$. toxicus (and other Rathayibacter species) may be translationally regulated through the utilization of rare TTA leucine codons, which are overrepresented in Rathayibacter TGCs, in a similar manner to antibiotic production in Streptomyces where LeutRNA UUA is temporally regulated and accumulates late in growth (Lawlor et al., 1987; Chater and Chandra, 2008). Unlike $R$. toxicus and the associated bacteriophage NCPPB3778, no bacteriophage have been implicated in toxin production by $R$. iranicus, R. agropyri, or R. woodii (Murray et al., 2017; Schneider et al., 2017).

The nematode vector Anguina funesta, and other Anguina species, are present in the United States (Meng et al., 2012). As discussed by Murray et al. (2017), the potential introduction of toxigenic Rathayibacter species, along with native Anguina species nematode populations, could have severe implications for United States agriculture. The widespread distribution and conservation of tunicaminyluracil-essential genes in diverse Rathayibacter species, collected from Australia, South Africa, Iran, Turkey, and the United States, warrants increased sampling of Rathayibacter species to determine the distribution of tunicaminyluracil-producing strains, the triggers of toxin production, and the role of tunicaminyluracil in Rathayibacter ecology.

\section{DATA AVAILABILITY STATEMENT}

All unpublished genome data have been deposited in GenBank SRA as BioProject PRJNA573074 (CA1 SAMN12797986, CA2 SAMN12797987, CA3 SAMN12797988, CA21 SAMN12797990, CA34 SAMN12797991, CA44 SAMN12797992, CA45 SAMN12797993, CA46 SAMN12797994,

\section{REFERENCES}

Altschul, S. F., Madden, T. L., Schäffer, A. A., Zhang, J., Zhang, Z., Miller, W., et al. (1997). Gapped BLAST and PSI-BLAST: a new generation of protein database search programs. Nucleic Acids Res. 25, 3389-3402. doi: 10.1093/nar/25.17.3389

Andrews, J. M., and Andrews, J. M. (2001). Determination of minimum inhibitory concentrations. J. Antimicrob. Chemother. 48(Suppl. 1), 5-16. doi: 10.1093/jac/ 48.suppl-1.5

Arif, M., Busot, G. Y., Mann, R., Rodoni, B., Liu, S., and Stack, J. P. (2016). Emergence of a new population of Rathayibacter toxicus: an ecologically complex, geographically isolated bacterium. PLoS One 11:e0156182. doi: 10. 1371/journal.pone.0156182

Bedhomme, S., Amorós-Moya, D., Valero, L. M., Bonifaci, N., Pujana, M. À, Bravo, I. G., et al. (2019). Evolutionary changes after translational challenges imposed by horizontal gene transfer. Genome Biol. Evol. 11, 814-831. doi: 10.1093/gbe/ evz031
CA80 SAMN12797997, CA49 SAMN12797996, CA47 SAMN12797995, FH164 SAMN12797998, FH176 SAMN12797999, FH 236 SAMN12798000).

\section{AUTHOR CONTRIBUTIONS}

MT designed the study, analyzed the sequences, and wrote the manuscript draft. AS assisted with sequence analysis. ED performed ANI analysis. TM and BS provided strains and sequences. JC and ER acquired funding and supervised the study. All authors read and approved the final manuscript.

\section{FUNDING}

Funding for this research was from the United States Department of Agriculture, Agricultural Research Service appropriated project 8044-22000-044-00D. ED was supported by a Provost's Distinguished Graduate Fellowship awarded by Oregon State University (OSU). This material is based upon work supported by the NSF Graduate Research Fellowship under Grant No. DGE-1314109 to ED. This work was also supported by a 2016 Farm Bill grant, Section 10201 administered through the USDA, Animal and Plant Health Inspection Service (APHIS) projects 3.0532.02 to JC and 13-8130-0247-CA and 14-8130-0367-CA to BS, TM, and ER.

\section{ACKNOWLEDGMENTS}

The authors thank Dr. Ian Riley for isolating and providing numerous Rathayibacter strains, Dr. James Stack for providing $R$. toxicus sequence data, and Dr. William Schneider for assistance in experimental design.

\section{SUPPLEMENTARY MATERIAL}

The Supplementary Material for this article can be found online at: https://www.frontiersin.org/articles/10.3389/fmicb. 2019.02914/full\#supplementary-material

Berry, P. H., and Wise, J. L. (1975). Wimmera rye grass toxicity in Western Australia. Aust. Vet. J. 51, 525-530. doi: 10.1111/j.1751-0813.1975.tb06903.x

Bird, A. F. (1981). "The Anguina-Coryneform association," in Plant Parasitic Nematodes, eds B. M. Zuckerman, and R. A. Rhode, (New York, NY: Academic Press), 303-323. doi: 10.1016/b978-0-12-782203-7.50018-2

Bourke, C. A., Carrigan, M. J., and Love, S. C. J. (1992). Flood plain staggers, a tunicaminyluracil toxicosis of cattle in northern New South Wales. Aust. Vet. Assoc. 69, 228-229. doi: 10.1111/j.1751-0813.1992.tb09932.x

Carver, T. J., Rutherford, K. M., Berriman, M., Rajandream, M. A., Barrell, B. G., and Parkhill, J. (2005). ACT: the artemis comparison tool. Bioinformatics 21, 3422-3423. doi: 10.1093/bioinformatics/bti553

Chandra, G., and Chater, K. F. (2008). Evolutionary flux of potentially bldAdependent Streptomyces genes containing the rare leucine codon TTA. Antonie van Leeuwenhoek 94, 111-126. doi: 10.1007/s10482-008-9231-5

Chater, K. F., and Chandra, G. (2008). The use of the rare UUA codon to define "expression space" for genes involved in secondary metabolism, development 
and environmental adaptation in Streptomyces. J. Microbiol. 46, 1-11. doi: 10. 1007/s12275-007-0233-1

Chen, W., Qi, J., Wu, P., Wan, D., Liu, J., Feng, X., et al. (2016). Natural and engineered biosynthesis of nucleoside antibiotics in Actinomycetes. J. Ind. Microbiol. Biotechnol. 43, 401-417. doi: 10.1007/s10295-015-1636-3

Chen, W., Qu, D., Zhai, L., Tao, M., Wang, Y., Lin, S., et al. (2010). Characterization of the tunicamycin gene cluster unveiling unique steps involved in its biosynthesis. Protein Cell 1, 1093-1105. doi: 10.1007/s13238-010-0127-6

Choi, Y., and Chan, A. P. (2015). PROVEAN web server: a tool to predict the functional effect of amino acid substitutions and indels. Bioinformatics 31, 2745-2747. doi: 10.1093/bioinformatics/btv195

Cunningham, I. J., and Hartley, W. J. (1959). Ryegrass staggers. N. Z. Vet. J. 7, 1-7.

Davis, E., Curran, G., Hetherington, W., Norms, D., Wise, G., Rothi, I., et al. (1995). Clinical, pathological and epidemiological aspects of flood plain staggers, a corynetoxicosis of livestock grazing Agrostis avenacea. Aust. Vet. J. 72, 187-190. doi: 10.1111/j.1751-0813.1995.tb03187.x

Davis, E., Weisberg, A., Tabima, J. F., Grunwald, N., and Chang, J. (2016). GallID: tools for genotyping gall-causing phytopathogenic bacteria. PeerJ 4:e2222. doi: $10.7717 /$ peerj.2222

Davis, E. W., Tabima, J. F., Weisberg, A. J., Lopes, L. D., Wiseman, M. S., Wiseman, M. S., et al. (2018). Evolution of the US biological select agent, Rathayibacter toxicus. mBio 9:e1280-81.

Doroghazi, J. R., Ju, K. S., Brown, D. W., Labeda, D. P., Deng, Z., Metcalf, W. W., et al. (2011). Genome sequences of three tunicamycin-producing Streptomyces strains, S. chartreusis NRRL 12338, S. chartreusis NRRL 3882, and S. lysosuperificus ATCC 31396. J. Bacteriol. 193, 7021-7022. doi: 10.1128/ JB.06262-11

Edgar, J. A., Frahn, J. L., Cockrum, P. A., Anderton, N., Jago, M. V., Culvenor, C. C. J., et al. (1982). Corynetoxins causative agents of annual ryegrass toxicity; their identification as tunicamycin group antibiotics. J. Chem. Soc. Chem. Commun. 4, 222-224. doi: 10.1039/c39820000222

Fattah, F. A., and Al-Assas, K. (2010). Histopathological comparison of galls induced by Anguina tritici with galls subsequently colonised by Rathayibacter tritici in wheat. Nematol. Mediterr. 38, 173-177.

Finn, R. D., Attwood, T. K., Babbitt, P. C., Bateman, A., Bork, P., Bridge, A. J., et al. (2017). InterPro in 2017-beyond protein family and domain annotations. Nucleic Acids Res. 45, D190-D199. doi: 10.1093/nar/gkw1107

Finnie, J. W. (2006). Review of corynetoxins poisoning of livestock, a neurological disorder produced by a nematode-bacterium complex. Aust. Vet. J. 84, 271-277. doi: 10.1111/j.1751-0813.2006.00019.x

Finnie, J. W., and Jago, M. V. (1985). Experimental production of annual ryegrass toxicity with tunicamycin. Aust. Vet. J. 62, 248-249. doi: 10.1111/j.1751-0813. 1985.tb07326x

Galloway, J. H. (1961). Grass seed nematode poisoning in livestock. J. Am. Vet. Med. Assoc. 139, 1212-1214.

Goris, J., Konstantinidis, K. T., Klappenbach, J. A., Coenye, T., Vandamme, P., and Tiedje, J. M. (2007). DNA-DNA hybridization values and their relationship to whole-genome sequence similarities. Int. J. Syst. Evol. Microbiol. 57, 81-91. doi: 10.1099/ijs.0.64483-0

Grewar, J. D., Allen, J. G., and Guthrie, A. J. (2009). Annual ryegrass toxicity in thoroughbred horses in ceres in the western cape province, South Africa. J. S. Afr. Vet. Assoc. 80, 220-223. doi: 10.4102/jsava.v80i4.211

Guindon, S., Dufayard, J. F., Lefort, V., Anisimova, M., Hordijk, W., and Gascuel, O. (2010). New algorithms and methods to estimate maximum-likelihood phylogenies: assessing the performance of PhyML 3.0. Syst. Biol. 59, 307-321. doi: 10.1093 /sysbio/syq010

Haag, J. R. (1943). Toxicity of nematode infested chewings fescue seed. Science 102, 406-407. doi: 10.1126/science.102.2651.406

Hoang, D. T., Chernomor, O., von Haeseler, A., Minh, B. Q., and Vinh, L. S. (2018). UFBoot2: improving the Ultrafast Bootstrap Approximation. Mol. Biol. Evol. 35, 518-522. doi: 10.1093/molbev/msx281

Jago, M. V., Payne, A. L., Peterson, J. E., and Bagust, T. J. (1983). Mechanism of action of corynetoxins, the causative agents of annual ryegrass toxicity. Toxicon 21, 195-197. doi: 10.1016/0041-0101(83)90189-7

Jensen, H. J. (1961). Nematodes Affecting Oregon Agriculture. Corvallis, OR: Oregon State University.

Kowalski, M. C., Cahill, D., Doran, T. J., and Colegate, S. M. (2007). Development and application of polymerase chain reaction-based assays for Rathayibacter toxicus and a bacteriophage associated with annual ryegrass (Lolium rigidum) toxicity. Aust. J. Exp. Agric. 47, 177-183. doi: 10.1071/EA05162

Kumar, S., Stecher, G., and Tamura, K. (2016). MEGA7: molecular evolutionary genetic analysis version 7.0. Mol. Biol. Evol. 33, 1870-1874. doi: 10.1093/ molbev/msw054

Land, M., Lapidus, A., Mayilraj, S., Chen, F., Copeland, A., del Rio, T. G., et al. (2009). Complete genome sequence of Actinosynnema mirum type strain (101 T). Stand. Genomic Sci. 1, 46-53. doi: 10.4056/sigs.21137

Lawlor, E. J., Baylis, H. A., and Chater, K. F. (1987). Pleiotropic morphological and antibiotic deficiencies result from mutations in a gene encoding a tRNAlike product in Streptomyces coelicolor A3(2). Genes Dev. 1, 1305-1310. doi: 10.1101/gad.1.10.1305

Li, W., Cowley, A., Uludag, M., Gur, T., McWilliam, H., Squizzato, S., et al. (2015). The EMBL-EBI bioinformatics web and programmatic tools framework. Nucleic Acids Res. 43, W580-W584. doi: 10.1093/nar/gkv279

McKay, A. C., Ophel, K. M., Reardon, T. B., and Gooden, J. M. (1993). Livestock deaths associated with Clavibacter toxicus/Anguina sp. infection in seedheads of Agrostis avenacea and Polypogon monspeliensis. Plant Dis. 77, 635-641.

Meng, S., Alderman, S., Fraley, C., Ludy, R., Sun, F., and Osterbauer, N. (2012). Identification of Anguina funesta from annual ryegrass seed lots in Oregon. Plant Heal. Prog. 13. doi: 10.1094/PHP-2012-1024-01-RS

Mullins, J. (1941). "Staggers" in animals. N. Zeal. J. Agric. Res. 62:169.

Murray, T. D., Agarkova, I., Alderman, S., Allen, J., Bulluck, R., Chitambar, J., et al. (2015). Recovery plan for Rathayibacter Poisoning Caused by Rathayibacter toxicus (syn. Clavibacter toxicus). National Plant Disease Recovery System, a Cooperative Project of the American Phytopathological Society and The United States Department of Agriculture. Available at: http://www.ars.usda.gov/ research/npdrs (accessed October 7, 2016).

Murray, T. D., Schroeder, B. K., Schneider, W. L., Luster, D. G., Sechler, A., Rogers, E. E., et al. (2017). Rathayibacter toxicus, Other Rathayibacter species inducing bacterial head blight of grasses, and the potential for livestock poisonings. Phytopathology 107, 804-815. doi: 10.1094/PHYTO-02-17-004 7-RVW

Payne, A. L., and Cockrum, P. A. (1988). Production of corynetoxins in vitro by Corynebacterium sp. isolated from annual ryegrass seedheads. Aust. J. Agric. Res. 39, 63-70. doi: 10.1071/AR9880063

Postnikova, E., Agarkova, I., Altundag, S., Eskandari, F., Sechler, A., Karahan, A., et al. (2009). Rathayibacter iranicus isolated from symptomless wheat seeds in Turkey. Plant Pathol. 58:796. doi: 10.1111/j.1365-3059.2009.02076.x

Price, P. C., Fisher, J. M., and Kerr, A. (1979). Annual ryegrass toxicity: parasitism of Lolium rigidum by a seed- gall forming nematode (Anguina sp.). Ann. Appl. Biol. 91, 359-369. doi: 10.1111/j.1744-7348.1979.tb06513.x

Riley, I. T., and McKay, A. C. (1990). Specificity of the adhesion of some plant pathogenic microorganisms to the cuticle of nematodes in the genus Anguina (Nematoda: Anguinidae). Nematologica 36, 90-103. doi: 10.1017/ CBO9781107415324.004

Riley, I. T., and McKay, A. C. (1991). Invasion of some grasses by Anguina funesta (Nematoda: Anguinidae) juveniles. Nematologica 37, 447-454. doi: 10.1017/ CBO9781107415324.004

Riley, I. T., Schmitz, A., and de Silva, P. (2001). Anguina australis, a vector for Rathayibacter toxicus in Ehrharta longiflora. Aust. Plant Pathol. 30, 171-175.

Riley, I. T., and Swart, A. (2004). Aspects of reproduction and survival of Anguina woodi. Aust. Plant Pathol. 33, 595-596. doi: 10.1071/AP01048

Riley, I. T., Swart, A., Postnikova, E., Agarkova, I., Vidaver, A. K., and Schaad, N. W. (2004). New association of a toxigenic Rathayibacter sp. and Anguina woodi in Ehrhata villosa var. villosa in South Africa. Phytopathology 94:S88.

Rutherford, K., Parkhill, J., Crook, J., Horsnell, T., Rice, P., Rajandream, M. A., et al. (2000). Artemis: sequence visualization and annotation. Bioinformatics 16, 944-945. doi: 10.1093/bioinformatics/16.10.944

Savory, E., Fuller, S., Weisberg, A., Thomas, W., Gordon, M., Stevens, D., et al. (2017). Evolutionary transitions between beneficial and phytopathogenic Rhodococcus challenge disease management. eLife 6:e30925. doi: 10.7554/eLife. 30925

Schneider, D. J. (1981). First report of annual ryegrass toxicity in the Republic of South Africa. Onderstepoort $J$ Vet.Res. 48, 251-255.

Schneider, W. L., Sechler, A. J., and Rogers, E. E. (2017). Complete genome sequence of Rathayibacter toxicus phage NCPPB3778. Genome Announc. 5:e00671-17. doi: 10.1128/genomeA.01388-17 
Schroeder, B. K., Schneider, W. L., Luster, D. G., Sechler, A., and Murray, T. D. (2018). Rathayibacter agropyri (non O'Gara 1916) comb. nov., nom. rev., isolated from western wheatgrass (Pascopyrum smithii). Int. J. Syst. Evol. Microbiol. 68, 1519-1525. doi: 10.1099/ijsem.0.002708

Sechler, A. J., Tancos, M. A., Schneider, D. J., King, J. G., Fennessey, C. M., Schroeder, B. K., et al. (2017). Whole genome sequence of two Rathayibacter toxicus strains reveals a tunicamycin biosynthetic cluster similar to Streptomyces chartreusis. PLoS One 12:e0183005. doi: 10.1371/journal.pone.0183005

Shaw, J. N., and Muth, O. H. (1949). Some types of forage poisoning in Oregon cattle and sheep. J. Am. Vet. Med. Assoc. 114, 315-317.

Sievers, F., Wilm, A., Dineen, D., Gibson, T. J., Karplus, K., Li, W., et al. (2011). Fast, scalable generation of high-quality protein multiple sequence alignments using Clustal Omega. Mol. Syst. Biol. 7:539. doi: 10.1038/msb.2011.75

Song, J. Y., Jeong, H., Yu, D. S., Fischbach, M. A., Park, H. S., Kim, J. J., et al. (2010). Draft genome sequence of Streptomyces clavuligerus NRRL 3585, a producer of diverse secondary metabolites. J. Bacteriol. 192, 6317-6318. doi: 10.1128/JB.00859-10

Stynes, B. A., and Bird, A. F. (1982). Development of galls induced in Lolium rigidum by Anguina agrostis. Phytopathology 72, 336-346.

Sullivan, M. J., Petty, N. K., and Beatson, S. A. (2011). Easyfig: a genome comparison visualizer. Bioinformatics 27, 1009-1010. doi: 10.1093/bioinformatics/btr039

Takatsuki, A., Arima, K., and Tamura, G. (1971). Tunicamycin, a new antibiotic: 1. Isolation and characterization of tunicamycin. J. Antibiot. 24, 215-223. doi: 10.7164/antibiotics. 24.215

Tkacz, J. S., and Lampen, J. O. (1975). Tunicamycin inhibition of polyisoprenyl $\mathrm{N}$-acetylglucosaminyl pyrophosphate formation in calf-liver microsomes. Biochem. Biophys. Res. Commun. 65, 248-257. doi: 10.1016/S0006-291X(75) 80086-6

Trifinopoulos, J., Nguyen, L. T., von Haeseler, A., and Minh, B. Q. (2016). W-IQTREE: a fast online phylogenetic tool for maximum likelihood analysis. Nucleic Acids Res. 44, W232-W235. doi: 10.1093/nar/gkw256

Vaser, R., Adusumalli, S., Leng, S. N., Sikic, M., and Ng, P. C. (2016). SIFT missense predictions for genomes. Nat. Protoc. 11, 1-9. doi: 10.1038/nprot.2015.123
Wattam, A. R., Davis, J. J., Assaf, R., Boisvert, S., Brettin, T., Bun, C., et al. (2017). Improvements to PATRIC, the all-bacterial bioinformatics database and analysis resource center. Nucleic Acids Res. 45, D535-D542. doi: 10.1093/nar/ gkw1017

Weber, T., Blin, K., Duddela, S., Krug, D., Kim, H. U., Bruccoleri, R., et al. (2015). AntiSMASH 3.0-a comprehensive resource for the genome mining of biosynthetic gene clusters. Nucleic Acids Res. 43, W237-W243. doi: 10.1093/ nar/gkv437

Widdick, D., Vior, N. M., Gomez-Escribano, J. P., Bibb, M. J., Royer, S. F., Wang, H., et al. (2018). Analysis of the tunicamycin biosynthetic gene cluster of Streptomyces chartreusis reveals new insights into tunicamycin production and immunity. Antimicrob. Agents Chemother. 62:e00130-18. doi: 10.1128/AAC. 00130- 18

Wyszynski, F. J., Hesketh, A. R., Bibb, M. J., and Davis, B. G. (2010). Dissecting tunicamycin biosynthesis by genome mining: cloning and heterologous expression of a minimal gene cluster. Chem. Sci. 1:581. doi: 10.1039/c0sc00325e

Disclaimers: Mention of trade names or commercial products in this publication is solely for the purpose of providing specific information and does not imply recommendation or endorsement by the U.S. Department of Agriculture. USDA is an equal opportunity provider and employer.

Conflict of Interest: The authors declare that the research was conducted in the absence of any commercial or financial relationships that could be construed as a potential conflict of interest.

Copyright (c) 2020 Tancos, Sechler, Davis, Chang, Schroeder, Murray and Rogers. This is an open-access article distributed under the terms of the Creative Commons Attribution License (CC BY). The use, distribution or reproduction in other forums is permitted, provided the original author(s) and the copyright owner(s) are credited and that the original publication in this journal is cited, in accordance with accepted academic practice. No use, distribution or reproduction is permitted which does not comply with these terms. 